\title{
Satisfaction of Body Image in Adolescents With Different Maturity Stages
}

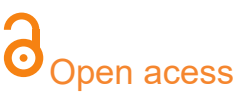

'Departamento de Educação Física, Universidade Federal do Rio Grande do Norte, Caixa Postal 1524 -

Campus Universitário Lagoa Nova, CEP 59078-970 Natal/RN - Brasil.

\section{Corresponding author:}

renata_aji@yahoo.com.br

Manuscript received: September 2017 Manuscript accepted: November 2017 Version of record online: December 2017

\author{
Renata Poliane Nacer de Carvalho Dantas ${ }^{1}$, Thaisys Blanc \\ dos Santos Simões ${ }^{1}$, Petrus Gantois Massa Dias dos Santos ${ }^{1}$, \\ Paulo Moreira da Silva Dantas ${ }^{1}$, Breno Guilherme Araújo \\ Tinoco Cabral ${ }^{1}$
}

\begin{abstract}
Introduction: Adolescence is a period marked by intense body modifications that occur differently according to the maturational stage and sex, which can generate different body image perceptions.

Objective: This study aims to compare and associate body image satisfaction in different maturational stages.

Methods: Overall, 207 adolescents of both sexes aged 10-12 years were evaluated. Maturation was estimated through an equation predictive of skeletal age and for the body image evaluation, the scale of silhouettes was used. The statistical tests used were chi-square and logistic regression (odds ratio) with respective confidence intervals $(95 \% \mathrm{Cl})$.
\end{abstract}

Results: There was a prevalence of body image dissatisfaction of $63.8 \%(p<0.001)$. In both sexes, subjects with accelerated maturation had greater body image dissatisfaction (girls $p=0.01$, boys $p=0.04)$, and desire to reduce their silhouette scale ( $p$ $<0.001$ ). Subjects with accelerated maturation were 2.88 more likely (Cl 95\% $1.03-8.05)$ of having body image dissatisfaction when compared to normal maturation; however, when adjusting for body mass index, the association lost its significance.

Conclusion: It could be concluded that body dissatisfaction perceived by young individuals is independent of sex, and there is an association between accelerated maturational stage 2.88 times higher than in the normal maturational stage in relation to body dissatisfaction, in which the body mass index appears to be the main predictor for body dissatisfaction.

Keywords: skeletal age, puberty, growth, body mass index

Suggested citation: Dantas RPNC, Simões TBS, Santos PGMD, Dantas PMS, Cabral BGAT. Satisfaction of Body Image in Adolescents With Different Maturity Stages. J Hum Growth Dev. 2017; 27(3):300-306. DOI: http://dx.doi.org/10.7322/jhgd.127574 


\section{INTRODUCTION}

Adolescence is marked by a period of transition between childhood and adulthood in which young people undergo major bodily transformations of somatic, metabolic and neuromotor order, inherent in their growth and development. Due to the changes that have taken place in society in the last decades, a growing acceleration in the development of children and adolescents has been observed. These changes often do not occur in a similar way among adolescents of the same chronological age, which is in part explained by changes in the rhythm of the pubertal process, mainly guided by the greater concentration of sex hormones ${ }^{1}$.

It is commonly reported that the body modifications experienced with the onset of the pubertal process involve an increase in body mass, fat percentage, pelvic enlargement and breast growth in girls ${ }^{2}$ and an increase in muscle mass in boys ${ }^{3}$. Therefore, these new discoveries in relation to size, appearance and body shape, enable young people to internalize in their mind a body image in search of the perfect body. This, in turn, generates negative feelings with the appearance $e^{4,5}$ and manifests differently in girls and boys ${ }^{6}$.

In contemporary society, body exaltation increasingly is observed as a form of identity, and the influence of the great media tends to lead young people to create an ideal of beauty that often leads to dissatisfaction

\section{METHODS}

\section{Study Design}

A cross-sectional design. First, researchers met with participants eligible for the sample. The adolescents were accompanied by their parents or guardians and were informed about the study procedures. The parents/ guardians were given a free and informed consent form, and adolescents who agreed to participate in the study were given a consent form. Data collection was performed in two days and included an anthropometric evaluation and the application of a scale to identify body image perception.

\section{Participants}

The sample consisted of adolescents age 10 12 years of both sexes from the public school system. Inclusion criterion was to be an adolescent with maximum age of 12 years. The validation of the silhouette scale made it necessary to exclude those with some cognitive limitation because it would make their body perception unfeasible. In accordance with the Declaration of Helsinki (2013) and Resolution 466/2012 of the National Health Council of Brazil, the procedures were previously authorized by the Ethics Research Committee under protocol No. 1.658.657/2016. The participation of adolescents was conditioned by the signing of the Free and Informed Consent Form (TCLE) and the Consent Form by parents and participants, respectively.

\section{Anthropometry}

Body mass and height were evaluated using an electronic scale (Filizola ${ }^{\circledR}$ 110, São Paulo, Brazil) with with their body image ${ }^{5,7}$. Body image is recognized as a subjective perception of the subject in relation to his or her own body, especially but not exclusively to physical appearance $^{8}$.

One of the instruments used and validated for the identification of body image in children and adolescents is the scale of silhouettes proposed by Kakeshita et al. ${ }^{9}$, which evaluates subjects' perception of satisfaction with their own body through a scale composed of 11 figures. These data present important practical applications because body dissatisfaction, based on the subjective evaluation of individuals through figures, has been pointed out as an important aspect of body image disorder, which is considered an important contributor to the adoption of unhealthy behaviors ${ }^{6,10}$.

In view of this, it is essential to evaluate the body image perception of adolescents during this process of intense changes in body composition inherent to the maturational process. In this way, it is possible to understand the impact these changes may be generating on adolescents' body perception according to their maturational stage, which may lead to a disturbance in the construction of their body image. Thus, the study aims to compare and associate the perception of body satisfaction according to the maturational development of adolescents.

capacity of $150 \mathrm{~kg}$, divisions of $1 / 10 \mathrm{~kg}$ and precision of $100 \mathrm{~g}$, as well as a stadiometer (Sanny ES2020 ${ }^{\circledR}$, São Bernardo Do Campo, Brazil) with scale of $0.5 \mathrm{~cm}$, respectively. Corrected arm and triceps skinfold perimeter was measured with Harpenden ${ }^{\circledR}$ adipometer (John Bull, London, England) with $0.2 \mathrm{~mm}$ precision and the biepicondile diameter of the humerus and femur with a metal clamp (Cescorf ${ }^{\mathbb{B}}$, Porto Alegre, Brazil).

Body mass index (BMI) was estimated using the body mass/height ${ }^{2}$ ratio. The following cut-off points were used for BMI classification: eutrophic, less than the 85th percentile; overweight, less than the 97th percentile, and obese, greater than the 97th percentile (World Health Organization $)^{2}$ taking into account age and sex. The reliability of measurements was tested by the test-retest coefficient ( $>$ 0.99). All procedures were performed by a single evaluator and followed guidelines of the International Society for the Advancement of Kinanthropometry (ISAK) ${ }^{11}$.

\section{Skeletal age and maturation}

Maturational development was evaluated through a mathematical model predicting skeletal age. The equation was determined based on anthropometric variables using a multiple regression model. The model included only variables that presented a significant correlation with skeletal age obtained through wrist X-ray, considered the gold standard. The predictor model was validated by Cabral et al. ${ }^{12}$ for the Brazilian population age 8-14 of both sexes (adjusted $r^{2}=0.741, \mathrm{SE}=1.24$ ), according to the equation below: 
Skeletal Age $=-11.620+7.004$ (height) $+1.226 . D_{\text {sex }}+$ 0.749 (age) $-0.068(\mathrm{Tr})+0.214(\mathrm{Acc})-0.588(\mathrm{Hd})+$ $0.388(F d)$.

where: $\operatorname{Tr}=$ tricipital skin fold, $\mathrm{Pcb}=$ arm circumference corrected, $\mathrm{DU}=$ humeral bone diameter, $\mathrm{Df}=$ femoral bone diameter and $\mathrm{D}_{\text {sex }}$ $=0$ for males and $D_{\text {sex }}=1$ for females.

\section{Body image}

For body image analysis, the scale of silhouettes proposed by Kakeshita et al ${ }^{9}$ was adapted for children and adolescents age 7-12. Participants were asked to point out which silhouette best represents their current physical appearance and which silhouette they would like to have (Figure 1). The evaluator was free of opinions when choosing the silhouettes. For the evaluation of body dissatisfaction, the ideal body image was subtracted from the current body image. If the result of subtraction was equal to zero, the individual was classified as satisfied with his or her body image; otherwise he or she was classified as dissatisfied (Figure 1).

\section{Statistical Analysis}

Descriptive statistic tests were performed for data characterization, and the Kolmogorov-Sminorv test was performed to verify their normality. To compare the relative frequencies of perception of body image satisfaction among maturational stages, the chi-square

\section{RESULTS}

Table 1 shows the comparison of the variables according to sex. Table 2 presents the comparison of perceived body satisfaction of the total sample and according to sex. Both sexes showed dissatisfaction between their real body image, reported in the silhouette scale, and the intended image $(>60 \%)$.

Table 1: Description and comparison of dependent variables between sex

\begin{tabular}{|c|c|c|c|}
\hline Variables & Male $(n=82)$ & Female $(n=125)$ & $\mathbf{p}$ \\
\hline \multicolumn{4}{|c|}{ Mean (Standard Deviation) } \\
\hline $\begin{array}{l}\text { Chronological } \\
\text { Age }\end{array}$ & $10.83(0.75)$ & $10.83(0.80)$ & 0.99 \\
\hline $\begin{array}{l}\text { Skeletal Age } \\
\text { (years) }\end{array}$ & $10.17(1.32)$ & $11.02(1.31)$ & $<0.001$ \\
\hline Body Mass (kg) & $40.43(10.51)$ & $39.63(11.66)$ & 0.62 \\
\hline Height (m) & $1.44(0.06)$ & $1.44(0.08)$ & 0.62 \\
\hline BMI $\left(\mathrm{kg} / \mathrm{m}^{2}\right)$ & $19.16(4.11)$ & $18.80(4.10)$ & 0.54 \\
\hline $\begin{array}{l}\text { Maturational } \\
\text { Stage }\end{array}$ & \multicolumn{2}{|c|}{ Absolute Frequency (Relative) } & \\
\hline Delayed & $28(34.1 \%)$ & $03(2.4 \%)$ & $<0.001$ \\
\hline Normal & $50(61 \%)$ & $100(80 \%)$ & $<0.001$ \\
\hline Early & $04(4.9)$ & $22(17.6 \%)$ & $<0.001$ \\
\hline \multicolumn{4}{|l|}{ BMI $\left(\mathrm{kg} / \mathrm{m}^{2}\right)$} \\
\hline Eutrophic & $43(52.4)$ & $79(63.2)$ & 0.001 \\
\hline Overweight & $13(15.9)$ & $22(17.6)$ & 0.289 \\
\hline Obese & $26(31.7)$ & $24(19.2)$ & 0.768 \\
\hline
\end{tabular}

The classification of maturational stages was obtained by subtracting the skeletal age in months by the chronological age in months. After subtraction, if the individual was between +12 and -12 in relation to the chronological age in months, he or she was classified as in normal classification, above +12 in accelerated classification, and less than -12 in delayed maturational classification $^{13}$.

Figure 1: Silhouette scale for children and adolescents (7-12 years old $)^{9}$.

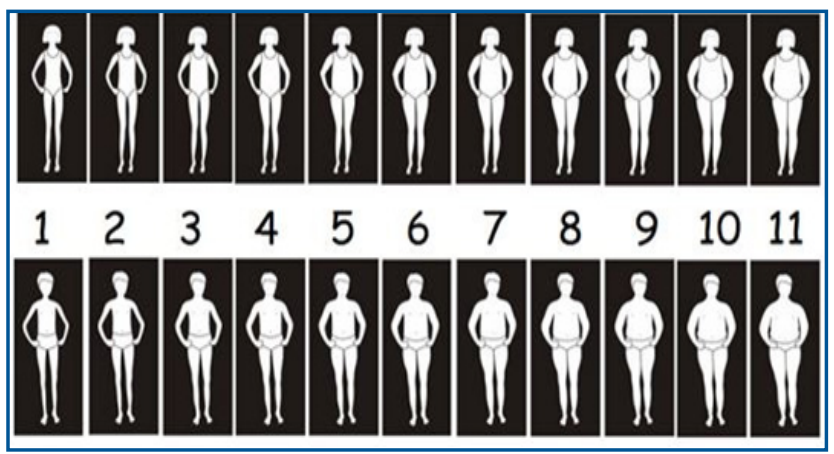

test was used. Logistic regression was used to analyze the association of body image dissatisfaction and odds ratio. The significance level was set at $p<0.05$ for all analyses. Analyses were carried out using the Statistical Package for the Social Sciences software - SPSS version 20.0.

Figures 2 and 3 show the comparison of perceived body image according to the maturational stages of girls and boys, respectively. Both figures show body dissatisfaction between the maturational stages with the participants wanting to decrease the silhouette.

Table 2: Comparison of index body image satisfaction frequency in both sex.

\begin{tabular}{lccc}
\hline Variables & Total (207) & $\begin{array}{c}\text { Boys (82) } \\
\text { Body Image }\end{array}$ & \multicolumn{3}{c}{ Gelative Frequency (125) } \\
Satisfied & $36.2 \%$ & $32.9 \%$ & $38.4 \%$ \\
Dissatisfied & $63.8 \%$ & $67.1 \%$ & $61.6 \%$ \\
$p$ value & $<0.001$ & 0.002 & 0.009 \\
$\begin{array}{l}\text { Want to } \\
\text { Increase }\end{array}$ & $35.6 \%$ & $36.4 \%$ & $35.1 \%$ \\
Want to & $64.4 \%$ & $63.6 \%$ & $64.9 \%$ \\
Decrease & & & \\
$\mathrm{p}$ value & 0.004 & 0.043 & 0.009 \\
\hline
\end{tabular}

Table 3 presents the logistic regression model of maturational stages related to body image satisfaction. There was significant association between early maturation and the reference group (normal stage), even after adjustment of chronological age and sex. Significant association was not verified, however, after insertion of the BMI classification in the model. 
Figure 2: Comparison of body image index according to maturational stages of girls

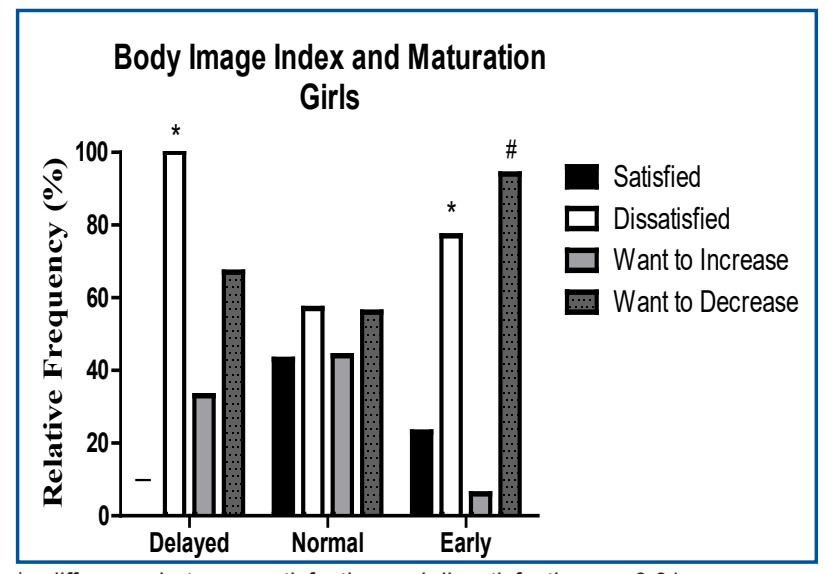

${ }^{*}=$ difference between satisfaction and dissatisfaction, $p=0.01$

\#= difference between want to increase and want to decrease, $p=0.001$
Figure 3: Comparison of body image index according to maturational stages of boys

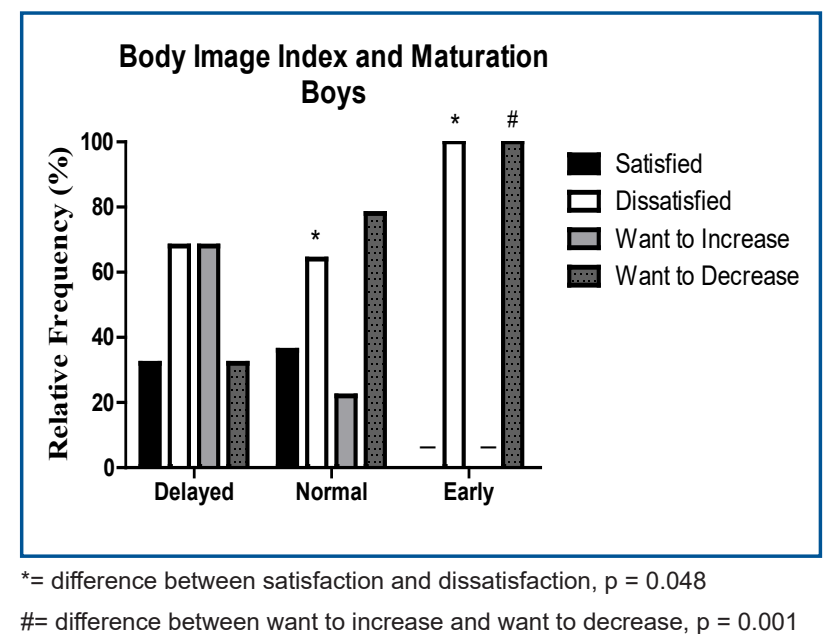

Table 3: Association between body image dissatisfaction and maturational stages by logistic regression

Odds Ratio (IC95\%)

Univariate Model

Maturation

Normal

Delayed

Early

Multivariate Model

A\#

1

$1.99(0.51-7.74)$
$\mathrm{B} \square$

1

${ }^{* *}$ reference category for logistic regression was body image satisfaction $\mathrm{Cl}=$ confident interval; OR = odds ratio; $\mathrm{A \#} \mathrm{=} \mathrm{adjusted} \mathrm{odds}$ ratio for (chronological age and sex); $\mathrm{B} \square=$ adjusted odds ratio for (chronological age, sex and body mass index); ${ }^{*}$ significant association.

\section{DISCUSSION}

The main findings of this study demonstrate that more than $60 \%$ of the adolescents in both sexes reported dissatisfaction with perceived body image, and participants in the accelerated maturational stage had the highest values. In addition, there was an association between body dissatisfaction and accelerated maturational stage; however, the association lost its significance after adjusting the model for chronological age, sex and BMI. In fact, previous studies involving Brazilian adolescents have reported high levels of body dissatisfaction ${ }^{7,14,15}$. It has been widely recognized that the construction of body dissatisfaction transcends the person's subjective perception towards a social perspective in which media sources have a strong appeal to a stereotyped pattern of beauty- in females thinness and in males increased strength and musculature- which can generate high standards of body dissatisfaction ${ }^{10,15,16}$.

When analyzing the subjective perception of body image of girls, it was observed that girls in delayed and accelerated maturational stages reported being dissatisfied with their body image $(p=0.01)$ and that those at accelerated stage have a desire to reduce their silhouette $(p<0.001)$. Despite the prevalence of girls with eutrophic classification, $71.8 \%$ of girls presented BMI classification above $85 \%$ (data not shown), which may be associated with their desire to reduce their silhouette. In fact, during biological development, there is an increase of body fat stocks in girls ${ }^{2}$, and this fact can be associated with the high body dissatisfaction observed. Corroborating this idea, previous studies have reported that girls with accelerated maturation have higher a $\mathrm{BMI}^{1,6}$ and are more likely to want to reduce their silhouette ${ }^{14,17,18}$.

Therefore, it is possible that body changes expressed during the pubertal process, in addition to the exposure and strong influence of society and media sources in relation to stereotyped patterns of beauty being a lean body, influence the high body dissatisfaction within this maturational stage, which increasingly affects girls even before their biological development ${ }^{5,16}$.

In addition, a study by Schneider et al. ${ }^{19}$, with German adolescents, reported body image dissatisfaction. These authors also warn about the possible negative effects that comments related to weight and diet have on the body image of young people.

When maturational stages of males are analyzed, $100 \%$ of those in the accelerated maturational stage had body image dissatisfaction $(\mathrm{p}=0.04)$, while some in the normal stage also had body dissatisfaction $(p<0.048)$. Interestingly, when we analyzed the direction of body dissatisfaction of boys in the accelerated stage, we found they desire to reduce their silhouette $(\mathrm{p}<0.001)$. This finding diverged from previous studies that reported that boys' body dissatisfaction was toward the desire to increase their silhouette in search of a stronger and more muscular profile ${ }^{20,21}$. When analyzing BMI, however, we found that $100 \%$ of boys in the accelerated stage were above the 97th percentile (data not shown), which may partially justify the desire to reduce the silhouette. In fact, previous studies have shown that high BMI is a strong predictor of body image dissatisfaction, which may lead youths to desire to reduce their silhouette ${ }^{17,21}$.

In view of these results, our findings suggest that 
maturational development is negatively associated with body satisfaction. After the logistic regression analysis, using odds ratios, participants classified in the accelerated maturational stage were 2.88 times more likely (95\% CI 1.03-8.05) of being dissatisfied with their body image as compared to those in the normal stage, and a significant association was observed after adjusting the model by chronological age and sex. When BMI was inserted in the model, however, the association lost its significance. Thus, our data reinforce the idea that BMI is an important predictor of body dissatisfaction ${ }^{6}$.

A classic study by Paxton et al. ${ }^{20}$ demonstrated that BMI is a strong predictor of body dissatisfaction at different developmental stages and in both sexes. In addition, these same authors reported that the idea of a lean body as beautiful reaches subjects in different age groups and often is associated with popularity and success. In contrast, overweight people are commonly exposed to inappropriate social situations (e.g., discrimination, social exclusion), which appears to generate this conflict with the perception of body dissatisfaction.

From a practical point of view, our data provide relevant information regarding the need for an early assessment of body satisfaction, especially during the puberty process, given the high prevalence of cases

\section{CONCLUSION}

In conclusion, it was observed that body dissatisfaction perceived by young individuals is independent of sex, with an association between accelerated maturational stage 2.88 times higher that of of body dissatisfaction pointed out in this study and in previous studies. In this sense, physical education professionals play a fundamental role in the identification of adolescents with body dissatisfaction when working with corporeity, making previous recognition possible. Therefore, it is necessary to adopt a professional approach within the different environments (social, educational, public health), aiming to raise awareness of body image acceptance to promote healthy habits among young people during this phase of body structure changes inherent in the pubertal process ${ }^{22}$.

Despite the relevant information presented in this study, some limitations need to be pointed out such as the cross-sectional design that makes a causal relationship impossible (multidimensional) and the effect that body dissatisfaction can generate in adolescents. Due to the fact that the scale of silhouettes was validated for adolescents up to 12 years of age, our sample was limited to this age group, making it impossible to analyze older subjects. In addition, it is noteworthy that, despite being a validated instrument and widely used in studies of the area, the scale of silhouettes may imply failures in the total body interpretation regarding fat mass distribution, inherent to the presentation of figures in the two-dimensional form ${ }^{7}$.

the normal stage in relation to body dissatisfaction. In addition, the body mass index appears to be the main predictor for body dissatisfaction, considering the loss of significance when adjusting for it in the model.

\section{REFERENCES}

1. Pinto VCM, Santos PGMD, Dantas MP, Araújo JPF, Cabral SAT, Cabral BGAT. Relationship between bone age, hormonal markers and physical capacity in adolescents. J Hum Growth Dev. 2017;27(1):7783. DOI: http://dx.doi.org/10.7322/jhgd.127658

2. Silva DAS, Pelegrini A, Petroski EL, Gaya ACA. Comparison between the growth of Brazilian children and adolescents and the reference growth charts: data from a Brazilian project. J Pediatr (Rio J). 2010;86(2):115-20. DOI: http://dx.doi.org/10.2223/JPED.1975

3. Goswami B, Singha Roy A, Dalui R, Bandyopadhyay A. Impact of pubertal growth on physical fitness. Am J Sport Sci Med. 2014;2(5A):34-9. DOI: http://dx.doi.org/10.12691/ajssm-2-5A-8

4. Duchesne A-P, Dion J, Lalande D, Bégin C, Émond C, Lalande G, et al. Body dissatisfaction and psychological distress in adolescents: Is self-esteem a mediator? J Health Psychol. 2017;22(12):1563-9. DOI: http://dx.doi.org/10.1177/1359105316631196

5. Evangelista LA, Aerts D, Alves GG, Palazzo L, Câmara S, Jacob MH. Body image perception in scholars of a school in the Brazilian north region. J Hum Growth Dev. 2016;26(3):385-92. DOI: http://dx.doi.org/10.7322/jhgd.122917

6. Mäkinen M, Puukko-Viertomies LR, Lindberg N, Siimes MA, Aalberg V. Body dissatisfaction and body mass in girls and boys transitioning from early to mid-adolescence: additional role of self-esteem and eating habits. BMC Psychiatry. 2012;12:35. DOI: http://dx.doi.org/10.1186/1471-244X-12-35

7. Glaner MF, Pelegrini A, Cordoba CO, Pozzobon ME. Associação entre insatisfação com a imagem corporal e indicadores antropométricos em adolescentes. Rev Bras Educ Física e Esporte. 2013;27(1):129-36. DOI: http://dx.doi.org/10.1590/S1807-55092013000100013

8. Cash TF. Encyclopedia of Body Image and Human Appearance. Vol. 1 e 2. Elsevier; 2012.

9. Kakeshita IS, Silva AIP, Zanatta DP, Almeida SS. Construção e fidedignidade teste-reteste de escalas de silhuetas brasileiras para adultos e crianças. Psicol Teor Pesq. 2009;25(2):263-70. DOI: http://dx.doi.org/10.1590/S0102-37722009000200015 
10. Rodgers RF, Paxton SJ, McLean SA. A biopsychosocial model of body image concerns and disordered eating in early adolescent girls. J Youth Adolesc. 2014;43(5):814-23. DOI: http://dx.doi.org/10.1007/s10964-013-0013-7

11. Marfell-Jones M, Olds T, Stewart A, Cartes L. International Standards for Anthropometric Assessment. 2006. p.137.

12. Cabral BGAT, Cabral SAT, Vital R, Lima KC, Alcantara T, Reis VM, et al. Equação preditora de idade óssea na iniciação esportiva através de variáveis antropométricas. Rev Bras Med Esporte. 2013;19(2):99-103. DOI: http://dx.doi.org/10.1590/S1517-86922013000200005

13. Malina R, Bouchard C, Bar-Or O. Growth, maturation, and physical activity. Champaign: Human Kinetics; 2004.

14. Petroski EL, Pelegrini A, Glaner MF. Motivos e prevalência de insatisfação com a imagem corporal em adolescentes. Cien Saude Coletiva. 2012;17(4):1071-7. DOI: http://dx.doi.org/10.1590/S1413-81232012000400028

15. Conti MA, Gambardella AMD, Frutuoso MFP. Insatisfação com a imagem corporal em adolescentes e sua relação com a maturação sexual body image dissatisfaction during adolescence and its relation to sexual maturation. Rev Bras Cresc Desenv Hum. 2005;15(2):36-44. DOI: http://dx.doi.org/10.7322/jhgd.19756

16. Van den Berg P, Paxton SJ, Keery H, Wall M, Guo J, Neumark-Sztainer D. Body dissatisfaction and body comparison with media images in males and females. Body Image. 2007;4(3):257-68. DOI: http://dx.doi.org/10.1016/j.bodyim.2007.04.003

17. Lawler M, Nixon E. Body dissatisfaction among adolescent boys and girls: the effects of body mass, peer appearance culture and internalization of appearance ideals. J Youth Adolesc. 2011;40(1):59-71. DOI: http://dx.doi.org/10.1007/s10964-009-9500-2

18. Scherer FC, Martins CR, Pelegrini A, Matheus SC, Petroski EL. Imagem corporal em adolescentes: Associação com a maturação sexual e sintomas de transtornos alimentares. J Bras Psiquiatr. 2010;59(3):198-202. DOI: http://dx.doi.org/10.1590/S0047-20852010000300005

19. Schneider S, Weiss M, Thiel A, Werner A, Mayer J, Hoffmann H, et al. Body dissatisfaction in female adolescents: Extent and correlates. Eur J Pediatr. 2013;172(3):373-84. DOI: http://dx.doi.org/10.1007/s00431-012-1897-z

20. Paxton SJ, Eisenberg ME, Neumark-Sztainer D. Prospective predictors of body dissatisfaction in adolescent girls and boys: A five-year longitudinal study. Dev Psychol. 2006;42(5):888-99. DOI: http://dx.doi.org/10.1037/0012-1649.42.5.888

21. Bucchianeri MM, Arikian AJ, Hannan PJ, Eisenberg ME, Neumark-Sztainer D. Body dissatisfaction from adolescence to young adulthood: Findings from a 10-year longitudinal study. Body Image. 2013;10(1):17. DOI: http://dx.doi.org/10.1016/j.bodyim.2012.09.001

22. Barros JSV, Lima MVM, Sampaio AN, Rocha SMBM, Dantas PMS, Batista SRA, et.al. Analysis of motor capacities in the maturational stages of female adolescents. J Hum Growth Dev. 2017;27(2):206-12. DOI: http://dx.doi.org/10.7322/jhgd.125018 


\section{Resumo}

Introdução: A adolescência é um período marcado por intensas modificações corporais que ocorrem de forma diferente de acordo com o estágio maturacional e sexo, o que pode gerar diferentes percepções da imagem corporal.

Objetivo: Comparar e associar a percepção de satisfação corporal de acordo com o desenvolvimento maturacional de adolescentes.

Método: Foram avaliados 207 adolescentes, escolares, de ambos os sexos, com idades entre 10 a 12 anos. A maturação foi estimada através de uma equação preditora da idade óssea e para avaliação da Imagem Corporal foi utilizada a escala de silhuetas. Os testes estatísticos utilizados foram qui-quadrado e regressão logística (odds rattio) com os respectivos intervalos de confiança (IC de 95\%).

Resultados: Verificou-se uma prevalência de insatisfação com a imagem corporal de 63,8\% ( $p<0,001)$. Em ambos os sexos os sujeitos que estão com a maturação acelerada possuem maior insatisfação com a Imagem corporal (meninas $p=0,01$; meninos $p=0,04$ ) desejando diminuir a sua escala de silhueta $(p<0,001)$. Os sujeitos com a maturação acelerada têm 2,88 mais chances (I.C 95\% 1,03-8,05) de insatisfação da imagem corporal quando comparado com o estágio normal, no entanto ao ajustar pelo índice de massa corporal a associação não foi significativa.

Conclusão: Pode-se concluir que a insatisfação corporal percebida pelos jovens é independente do sexo, sendo encontrada uma associação entre o estágio maturacional acelerado 2,88 vezes maior do que no estágio normal em relação à insatisfação corporal, no qual o índice de massa corporal aparenta ser o principal preditor para esta insatisfação.

Palavras-chave: idade óssea, puberdade, crescimento, índice de massa corporal

- The authors (2017), this article is distributed under the terms of the Creative Commons Attribution 4.0 International License (http://creativecommons.org/licenses/by/4.0/), which permits unrestricted use, distribution, and reproduction in any medium, provided you give appropriate credit to the original author(s) and the source, provide a link to the Creative Commons license, and indicate if changes were made. The Creative Commons Public Domain Dedication waiver (http://creativecommons.org/publicdomain/ zero/1.0/) applies to the data made available in this article, unless otherwise stated. 